\title{
Oxidation of biogenic and water-soluble compounds in aqueous and organic aerosol droplets by ozone: a kinetic and product analysis approach using laser Raman tweezers
}

Article

Published Version

King, M.D., Pfrang, C., Hughes, B.R., Thompson, K.C. and Ward, A.D. (2008) Oxidation of biogenic and water-soluble compounds in aqueous and organic aerosol droplets by ozone: a kinetic and product analysis approach using laser Raman tweezers. Faraday Discussions, 137. pp. 173-192. ISSN 13596640 doi: https://doi.org/10.1039/b702199b Available at https://centaur.reading.ac.uk/11395/

It is advisable to refer to the publisher's version if you intend to cite from the work. See Guidance on citing.

To link to this article DOI: http://dx.doi.org/10.1039/b702199b

Publisher: The Royal Society of Chemistry

All outputs in CentAUR are protected by Intellectual Property Rights law, including copyright law. Copyright and IPR is retained by the creators or other copyright holders. Terms and conditions for use of this material are defined in the End User Agreement. 


\section{www.reading.ac.uk/centaur}

\section{CentAUR}

Central Archive at the University of Reading

Reading's research outputs online 


\title{
Oxidation of biogenic and water-soluble compounds in aqueous and organic aerosol droplets by ozone: a kinetic and product analysis approach using laser Raman tweezers
}

\author{
Martin D. King, ${ }^{* a}$ Katherine C. Thompson, ${ }^{b}$ Andrew D. Ward, ${ }^{c}$ \\ Christian Pfrang $\dagger^{a}$ and Brian R. Hughes ${ }^{b}$
}

\author{
Received 12th February 2007, Accepted 20th March 2007 \\ First published as an Advance Article on the web 30th August 2007 \\ DOI: $10.1039 / b 702199 b$
}

The results of an experimental study into the oxidative degradation of proxies for atmospheric aerosol are presented. We demonstrate that the laser Raman tweezers method can be used successfully to obtain uptake coefficients for gaseous oxidants on individual aqueous and organic droplets, whilst the size and composition of the droplets is simultaneously followed. A laser tweezers system was used to trap individual droplets containing an unsaturated organic compound in either an aqueous or organic (alkane) solvent. The droplet was exposed to gas-phase ozone and the reaction kinetics and products followed using Raman spectroscopy. The reactions of three different organic compounds with ozone were studied: fumarate anions, benzoate anions and $\alpha$-pinene. The fumarate and benzoate anions in aqueous solution were used to represent components of humic-like substances, HULIS; $\alpha$-pinene in an alkane solvent was studied as a proxy for biogenic aerosol. The kinetic analysis shows that for these systems the diffusive transport and mass accommodation of ozone is relatively fast, and that liquid-phase diffusion and reaction are the rate determining steps. Uptake coefficients, $\gamma$, were found to be $(1.1 \pm 0.7) \times 10^{-5},(1.5 \pm 0.7) \times 10^{-5}$ and $(3.0-7.5) \times 10^{-3}$ for the reactions of ozone with the fumarate, benzoate and $\alpha$-pinene containing droplets, respectively. Liquid-phase bimolecular rate coefficients for reactions of dissolved ozone molecules with fumarate, benzoate and $\alpha$-pinene were also obtained: $k_{\text {fumarate }}=$ $(2.7 \pm 2) \times 10^{5}, k_{\text {benzoate }}=(3.5 \pm 3) \times 10^{5}$ and $k_{\alpha \text {-pinene }}=(1-3) \times 10^{7} \mathrm{dm}^{3}$ $\mathrm{mol}^{-1} \mathrm{~s}^{-1}$. The droplet size was found to remain stable over the course of the oxidation process for the HULIS-proxies and for the oxidation of $\alpha$-pinene in pentadecane. The study of the $\alpha$-pinene/ozone system is

\footnotetext{
${ }^{a}$ Department of Geology, Royal Holloway University of London, Egham, Surrey, UK TW20 0EX.E-mail:m.king@gl.rhul.ac.uk; Fax: + 44 (0)1784 414038

${ }^{b}$ School of Biological and Chemical Sciences, Birkbeck University of London, Malet Street, London, UK WC1E $7 H X$

${ }^{c}$ Central Laser Facility, CCLRC Rutherford Appleton Laboratory, Chilton, Oxon, $U K O X 110 Q X$
}

$\uparrow$ Present address: Department of Chemistry, University of Reading, P.O. Box 224, Whiteknights, Reading, UK RG6 6AD. 
the first using organic seed particles to show that the hygroscopicity of the particle does not increase dramatically over the course of the oxidation. No products were detected by Raman spectroscopy for the reaction of benzoate ions with ozone. One product peak, consistent with aqueous carbonate anions, was observed when following the oxidation of fumarate ions by ozone. Product peaks observed in the reaction of ozone with $\alpha$-pinene suggest the formation of new species containing carbonyl groups.

\section{Introduction}

Particulate matter is abundant in the troposphere and significantly influences both its chemical and physical characteristics. ${ }^{1}$ The effect of aerosol on radiative properties and cloud formation was identified by the intergovernmental panel on climate change, IPCC, to be the largest uncertainty in assessing the impact of particulate matter on climate change. ${ }^{2}$ The impacts of inorganic aerosol on cloud formation has been examined and that of organic aerosol has started to be addressed (indirect aerosol effects were recently reviewed ${ }^{3}$ ), but are yet to be well explored. Atmospheric aerosol is not chemically inert; particles and droplets may provide sites for chemical reaction. Reactions will alter the chemical and physical properties of cloud droplets (and hence potentially their size, in line with adapted Köhler theory ${ }^{4}$ ) consequently altering how the droplets interact with solar radiation and thus influence the climate.

We explore the reactions between a ubiquitous pollutant, ozone, and aerosol droplets containing unsaturated organic species in aqueous and non-aqueous solutions. The oxidation of fumarate (1) and benzoate (2) ions in aqueous solution, as proxies for HUmic-LIke Substances, HULIS, and the terpenoid compound $\alpha$-pinene (3) in organic aerosol, as a proxy for biogenic non-aqueous aerosol, were studied:

$$
\text { + }+\mathrm{O}_{3} \rightarrow \text { products }
$$

This research builds on our previous work studying droplet size and composition during the oxidation of a film of oleic acid on aqueous aerosol. ${ }^{5}$

The term HULIS has been used to describe the organic material found in rain, fog and aerosol that resembles the organic material in river/sea water and soils. HULIS are probably formed in aerosol by chemical reactions as opposed to humic material which is produced in river water and soils by the breakdown of biological substances. HULIS may be present in as much as $20-50 \%$ of aerosol particles. ${ }^{6}$ The reports of HULIS in clouds, fog and aerosol have been reviewed by Graber and Rudich. ${ }^{6}$ Humic and HULIS material can be difficult to chemically characterise, because it defies speciation and molecular definition owing to its complexity, size and non-uniformity. However, consensus is now forming on a model HULIS structure consisting of an aromatic core bearing substituted aliphatic chains with $-\mathrm{COOH}$, 
$-\mathrm{CH}_{2} \mathrm{OH},-\mathrm{COCH}_{3}$ groups. ${ }^{7}$ Indeed one study found that HULIS was composed of $n$-alkanoic acids, $\omega$-alkenoic, benzoic mono- di- and tri-carboxylic acids, methoxy and acetic and methoxy benzoic acid and a few nitrogen containing glycerine derivatives. ${ }^{8}$ Kiss et al. ${ }^{9}$ attempted to determine the "size" of a HULIS "molecule" and suggested 40-520 $\mathrm{Da}$ (where $1 \mathrm{Da}$ is equal to $1 / 12$ of the mass of an unbound atom of ${ }^{12} \mathrm{C}$ at rest and in its ground state). HULIS is produced from marine, biomass burning and small terrestrial sources, and in secondary aerosol formation (condensation, reaction and oligomerization). An oligomer is a molecule that consists of a finite number identical monomer units. The latter route to HULIS formation is intriguing and HULIS has been shown to be formed by reaction of $\mathrm{OH}$ radical with 3,5-dihydroxybenzoic acid on the time scale of hours to days ${ }^{10}$ by oligomerization. The presence and/or oxidation of HULIS in clouds, fog and aerosol may lead to droplet activation (cloud formation): ${ }^{11}$ droplets containing HULIS were found to activate at lower diameters and thus make cloud formation more facile. Dinar et $a l .{ }^{11}$ also found that HULIS extracted from daytime filter samples has a lower critical supersaturation diameter than night-time samples; strongly suggesting the reaction with daytime atmospheric oxidants to be important in oxidising HULIS and to increase the hygroscopic properties of cloud droplets. Thus the reactions between HULIS and atmospheric oxidants such as ozone need to be studied to determine if they (1) lower the critical supersaturation required for cloud formation and (2) lead to the formation of oligomers. The rate for these reactions must be quantified to establish if they are atmospherically important.

The biosphere produces the large majority of volatile organic compounds, VOCs, emitted into the atmosphere. ${ }^{12}$ Oxidation of these biogenic VOCs tends to produce low vapour pressure compounds that partition to particulate matter to form secondary organic aerosol, SOA, ${ }^{13-15}$ although some large biogenic VOCs (e.g. sesquiterpenes) may partition directly to aerosol particulate matter. Secondary organic aerosol may affect the critical saturation ratios of clouds, lead to global dimming and provide a surface for further heterogeneous chemistry to occur. ${ }^{16}$ The surface chemistry on SOA leads to the formation of large compounds and oligomers with very low vapour pressures. ${ }^{17-22}$ The precursor biogenic VOC typically contains a carbon-carbon double bond or an aromatic moiety. The composition and aqueous oxidation chemistry of a SOA particle influences subsequent oligomer formation. ${ }^{23}$ Two of the largest components of the biogenic VOC budget are isoprene and $\alpha$-pinene. ${ }^{12}$ In this study we use $\alpha$-pinene in a long chain alkane to represent a biogenic VOC in an "organic" particle. We selected $\alpha$-pinene as its oxidation in the gas-phase has been previously studied. ${ }^{23-27}$

Some of the first studies were performed by Thurn and Kiefer, Biswas et al. and Omori et al ${ }^{28-30}$ Zellner and co-workers have used optical levitation to study the phase behaviour of inorganic acids relevant of the atmosphere ${ }^{31-34}$ and recently employed optical levitation to measure hygroscopic growth curves for ammonium sulfate and glutaric acid solutions in an aqueous droplet. ${ }^{35}$ The optical leviatation technique traps a particle by balancing the gravitational and the scattering/radiation pressure forces on the particle. The optical tweezers traps a particle using the gradient force and provide a "3-D" trap unlike optical levitation. The history and recent developments of optical tweezers techniques in relation to aerosol trapping has been reviewed by McGloin ${ }^{36}$ and will not be repeated in the framework of this paper. Reid, Ward and co-workers have used laser tweezers to study hygroscopic growth, ${ }^{37,38}$ and coagulation of two droplets. ${ }^{39,40}$ Reid has also studied morphological Raman resonances (cavity enhanced Raman scattering) to size particles ${ }^{41,42}$ and together with McGloin to develop new optical traps. ${ }^{43}$ Ward and co-workers have also used laser tweezers to study aerosol chemistry relevant to atmospheric chemistry. ${ }^{5}$

In the work presented here we used the laser Raman optical-tweezers technique to trap aqueous or organic droplets containing benzoate ions, fumarate ions or 
$\alpha$-pinene in a gaseous flow of humidified oxygen. The particles were subjected to a flow of ozone (ppm range) whilst the particle size was monitored using optical microscopy and changes in particle composition were detected with Raman spectroscopy. Particles of 2-10 microns were trapped in the focus of an Ar-ion laser and could be held for up to $6 \mathrm{~h}$ during oxidation, scattered laser light was collected and analysed to produce a Raman spectrum of the organic reactant and products. The aim of this work was to demonstrate the performance of laser-Raman optical-tweezers for studying atmospheric reactions relevant to cloud droplet size and dynamics.

\section{Experimental}

\subsection{Laser Raman tweezers}

The set-up of the laser Raman tweezers consisted of an Ar-ion laser source (Coherent Innova 90-5-UV), with an emission wavelength of $514.5 \mathrm{~nm}$. The beam is passed through two sets of beam expansion optics ${ }^{44}$ which are anti-reflection coated for the laser wavelength. The optics expand the laser beam to slightly overfill the aperture of the water-immersion objective lens $(\times 63$, NA 1.2, Leica Microsystems) and also creates a conjugate focal plane at a steering mirror that is used to manipulate the optical trapping position. Before entering the Leica DM-IRB microscope the beam is passed through a custom-made dichroic (Ingcrys Ltd) that transmits $514.5 \mathrm{~nm}$ but reflects from $520 \mathrm{~nm}$ to $630 \mathrm{~nm}$ (i.e. the Stokes Raman scattering). The laser beam is directed upwards into the objective lens, using a second dichroic mirror that reflects $500 \mathrm{~nm}$ to $630 \mathrm{~nm}$ (i.e. laser and Raman lines) and transmits the remaining visible light for optical imaging. The laser beam is tightly focused, forming the optical trap, and backscattered Raman shifted light from the trapped aerosol droplet is collimated by the objective lens and passes back along the same optical pathway. The signal is reflected from both dichroic mirrors and through a $514.5 \mathrm{~nm}$ notch filter (Kaiser Optical Systems, HNF-5145) to remove any traces of the Rayleigh scattering. It is then focussed into a spectrograph (Acton Research Corporation SP500i, 1200 groove blazed at $500 \mathrm{~nm}$ ) and imaged onto a deep depletion CCD camera (Princeton Instruments Spec10:400 BR/LN). In a typical experiment, the power of the source was attenuated to $12 \mathrm{~mW}$ at laser focus and Raman spectra were collected continuously with a $10 \mathrm{~s}$ scan time for each trapped droplet. In all cases, background spectra were obtained when the droplet was released from the trap, and these signals were subtracted from the droplet spectra. To allow observation of the trapped particles, visible light from the microscope lamp is used to obtain brightfield images of the sample, recorded using a CCD camera.

\subsection{Aerosol generation and reaction}

The droplets were trapped inside a small aluminium cell that had two cover-slip glass windows to allow the passage of the laser beam from below and to image the particle from above. The cell had a simple stainless steel tube exhaust and entrance. Three gas streams were combined and entered the cell: a flow of dry oxygen that passed through an ozone generator (where oxygen was exposed to the emission from a mercury pen-ray lamp), a flow of dry nitrogen which was humidified by bubbling through pure water, and a flow from an ultrasonic nebulizer which provided the source of the initial droplet. All flows were at atmospheric pressure and controlled by needle valves. The oxygen and nitrogen flows, typically in the range $0.1-1 \mathrm{~cm}^{3} \mathrm{~s}^{-1}$, were altered to change the relative humidity and ozone concentration in the cell, but were kept constant during any one experiment. The relative humidity was measured at the entrance and exhaust of the reaction chamber. The ozone concentration ( $\sim 0.5-2 \mathrm{ppm}$ in the cell) was calibrated by bubbling through potassium iodide solutions and titrating the molecular iodine formed with thiosulfate. 
Aerosol was generated by nebulizing aqueous solutions of sodium benzoate, sodium fumarate, or solutions of $\alpha$-pinene in dodecane or in pentadecane, using a commercial ultrasonic nebulizer. The nebulizer was switched on until a droplet was trapped in the optical tweezers and then the flow from the nebulizer was switched off. The droplet was allowed to equilibrate with the relative humidity in the cell. Collisions with the cell walls removed other droplets. The sodium benzoate solutions $\left(0.086 \mathrm{~mol} \mathrm{dm}^{-3}\right)$ were prepared by dissolving sodium benzoate in pure water. Sodium fumarate solutions $\left(0.086 \mathrm{~mol} \mathrm{dm}^{-3}\right)$ were prepared by dissolving fumaric acid in a dilute solution of sodium hydroxide. The $\mathrm{pH}$ of the solutions of sodium benzoate and sodium fumarate were 8.6 and 10 .

A typical experiment would start with trapping a particle within the reaction cell and the scattered laser light would be collected over 10 or $30 \mathrm{~s}$ to obtain the Raman spectrum. A digital image of the particles was also collected every 10 or $30 \mathrm{~s}$. The laser power and optics would be adjusted to bring the particle into focus, so that it was optimally trapped. The humidity in the reaction chamber was allowed to equilibrate with the entering gas-flows for 5-30 minutes to allow the particle size to stabilise. A constant humidified gas stream ensured the particle quickly attained its equilibrium size. The particle was normally held about $50 \mu \mathrm{m}$ above the surface of the cell. The relative humidity $50 \mu \mathrm{m}$ above the cell surface was assumed to be the same as that of the humidified gas stream. The ozone was then allowed to enter the cell. Some experiments were conducted with the ozone present before the equilibration. At the end of the experiment the particle was released from the optical trap by blocking the laser beam momentarily and Raman spectra were continued to be collected in case of any spurious measurement - this was never the case. The digital photography was size-calibrated by photographing a microscope stage graticule with $10 \mu \mathrm{m}$ spacing. Seven pixels on the CCD camera approximately correspond to $1 \mu \mathrm{m}$, thus the precision of the particle sizing may be as good as $0.13 \mu \mathrm{m}$, however we quote an error in the size of the particle of $\sim 0.25 \mu \mathrm{m}$. The particle images were sized manually using in-house image analysis software. The Raman spectra were used to follow the loss of benzoate, fumarate and $\alpha$-pinene and the growth of any products. The amount of benzoate, fumarate and $\alpha$-pinene was measured by subtraction of a proportion of a reference spectrum for these compounds. Subtraction of a complete spectrum overcomes the interfering effect of morphological Raman resonances (or cavity-enhanced Raman scattering) that sometimes appear in the spectra and affect the intensity of the peaks (NB Fig. 4 demonstrates such a peak). Morphological Raman resonances (or cavity-enhanced Raman scattering $)^{30,45-47}$ were not used to size the particles as they were observed in some spectra but not all.

\section{Results}

From the laser Raman tweezers experiments we obtained information on reaction kinetics, particle size and products, and shall report each set of results separately.

\subsection{Reactive uptake model and kinetic analysis}

The reaction of gas-phase ozone with an organic molecule in an aqueous droplet proceeds via several consecutive and simultaneous processes. The ozone must first diffuse to the droplet, accommodate at the surface of the particle, and then incorporate itself within the bulk phase of the droplet, or alternatively ozone may react with the organic molecule at the surface of the droplet. The system can be described by a set of coupled differential equations which can be solved for limiting cases. ${ }^{48-51}$ A resistance model is commonly used to analyse gas-particle reactions in laboratory studies of atmospheric chemistry. ${ }^{52-55}$ Each process is treated as a "conductor" and can be added in series or parallel like 
resistors in an electronic circuit to give the overall uptake coefficient, $\gamma$, of a gasphase species (i.e. ozone) on a particle or droplet. This approach assumes that the processes can all be treated independently. Each conductance, $\Gamma$, is normalised to the rate of gas-particle collisions. The conductances are gas-phase transport to the surface, $\Gamma_{\mathrm{g}}$, accommodation at the surface of the particle, $\alpha$, solubility/incorporation into the bulk of the particle, $\Gamma_{\text {sol }}$, and reaction in the bulk aqueous phase of the particle, $\Gamma_{\mathrm{rxn}}$. The conductances yield the following equation:

$$
\frac{1}{\gamma}=\frac{1}{\Gamma_{\mathrm{g}}}+\frac{1}{\alpha}+\frac{1}{\Gamma_{\mathrm{rxn}}+\Gamma_{\mathrm{sol}}}
$$

Table 1 demonstrates that in our experimental conditions, the diffusive transport of ozone to the surface of the particle and mass accommodation of ozone on the aqueous droplet are typically fast, not rate-limiting processes, and can be neglected in the determination of the uptake coefficient, $\gamma$. The aqueous-phase diffusion and reaction are the rate-determining steps. Table 1 lists characteristic times for the separate process described above. The characteristic time of gas-phase transport of ozone to the particle can be calculated for a particle of radius, $r=4 \mu \mathrm{m}$, and a gas-phase diffusion constant of ozone in air, $D_{\mathrm{g}}\left(\mathrm{O}_{3}\right)=1.78 \times 10^{-5} \mathrm{~m}^{2} \mathrm{~s}^{-1}$ at $T=293 \mathrm{~K}^{56}$ The mass accommodation characteristic time is given by the mass accommodation coefficient for ozone on water, $\alpha=1 \times 10^{-2},{ }^{57}$ Henry's law constant, $\mathrm{H}$, for $\mathrm{O}_{3}$ in the solution, the gas constant, $R=8.205 \times 10^{-5} \mathrm{~m}^{3} \mathrm{~atm}$ $\mathrm{K}^{-1} \mathrm{~mol}^{-1}$, the temperature, $T=293 \mathrm{~K}$, the liquid-phase diffusion constant, $D_{l}\left(\mathrm{O}_{3}\right)$ and the average molecular speed in the gas-phase, $\bar{v}$. For ozone in aqueous solution $H=12.17 \mathrm{~mol} \mathrm{~m}^{-3} \mathrm{~atm}^{-1}$ was used taking into account ionic strength and temperature corrections ${ }^{57}$ to replicate experimental conditions. Two values of Henry's law constant for ozone in organic liquid were found in the literature: 80 and $480 \mathrm{~mol} \mathrm{~m}^{-3} \mathrm{~atm}^{-1}$. A value of $D_{l}\left(\mathrm{O}_{3}\right)=1.19 \times 10^{-9} \mathrm{~m}^{2} \mathrm{~s}^{-1}$ was used for the liquid-phase diffusion constant of ozone in an aqueous droplet and a value of $D_{l}\left(\mathrm{O}_{3}\right)$ $=1.0 \times 10^{-9} \mathrm{~m}^{2} \mathrm{~s}^{-1}$ was employed for the organic liquid media. ${ }^{58}$ The mass accommodation coefficient for ozone on an organic droplet has not been reported, we thus had to use the value of $\alpha=10^{-2}$ reported for aqueous droplets. ${ }^{57}$ It is likely that the mass accommodation coefficient has a larger value for organic liquids as ozone is typically a factor of seven more soluble in organic compounds than in water. ${ }^{59}$

Table 1 considers the characteristic time for reaction of ozone in the bulk liquid phase of the droplet. Rate coefficients considered for the reaction of ozone with fumarate ions in aqueous solutions are $k_{1}>1 \times 10^{5} \mathrm{dm}^{3} \mathrm{~mol}^{-1} \mathrm{~s}^{-1} 60$ and for reaction with benzoate ions $k_{2}=1.2 \mathrm{dm}^{3} \mathrm{~mol}^{-1} \mathrm{~s}^{-1}, 61$ and $3.5 \times 10^{5} \mathrm{dm}^{3} \mathrm{~mol}^{-1} \mathrm{~s}^{-1}$ (this work). For the examples listed here [benzoate] $=0.086 \mathrm{~mol} \mathrm{dm}^{-3}$, and [fumarate] $=0.086 \mathrm{~mol} \mathrm{dm}{ }^{-3}$. Table 1 lists another important quantity: the diffuso-reactive length, $l$. This parameter indicates how far an ozone molecule may diffuse before it reacts in the liquid phase. Large diffuso-reactive lengths suggest fast diffusion and/or slow kinetics, whereas small diffuso-reactive lengths indicate that reaction dominates over diffusion. ${ }^{51}$ For the systems studied here, eqn (I) reduces to

$$
\frac{1}{\gamma}=\frac{1}{\Gamma_{\mathrm{rxn}}+\Gamma_{\mathrm{sol}}}
$$

i.e. the uptake of ozone on aqueous particles containing the organic compounds considered here will depend predominantly on the rate of change of the ozone concentration in the particle by reaction and diffusion. Smith et al. ${ }^{58}$ have described this situation using the equation

$$
\frac{\partial\left[\mathrm{O}_{3}\right]}{\partial t}=D \nabla^{2}\left[\mathrm{O}_{3}\right]-k\left[\mathrm{O}_{3}\right]
$$




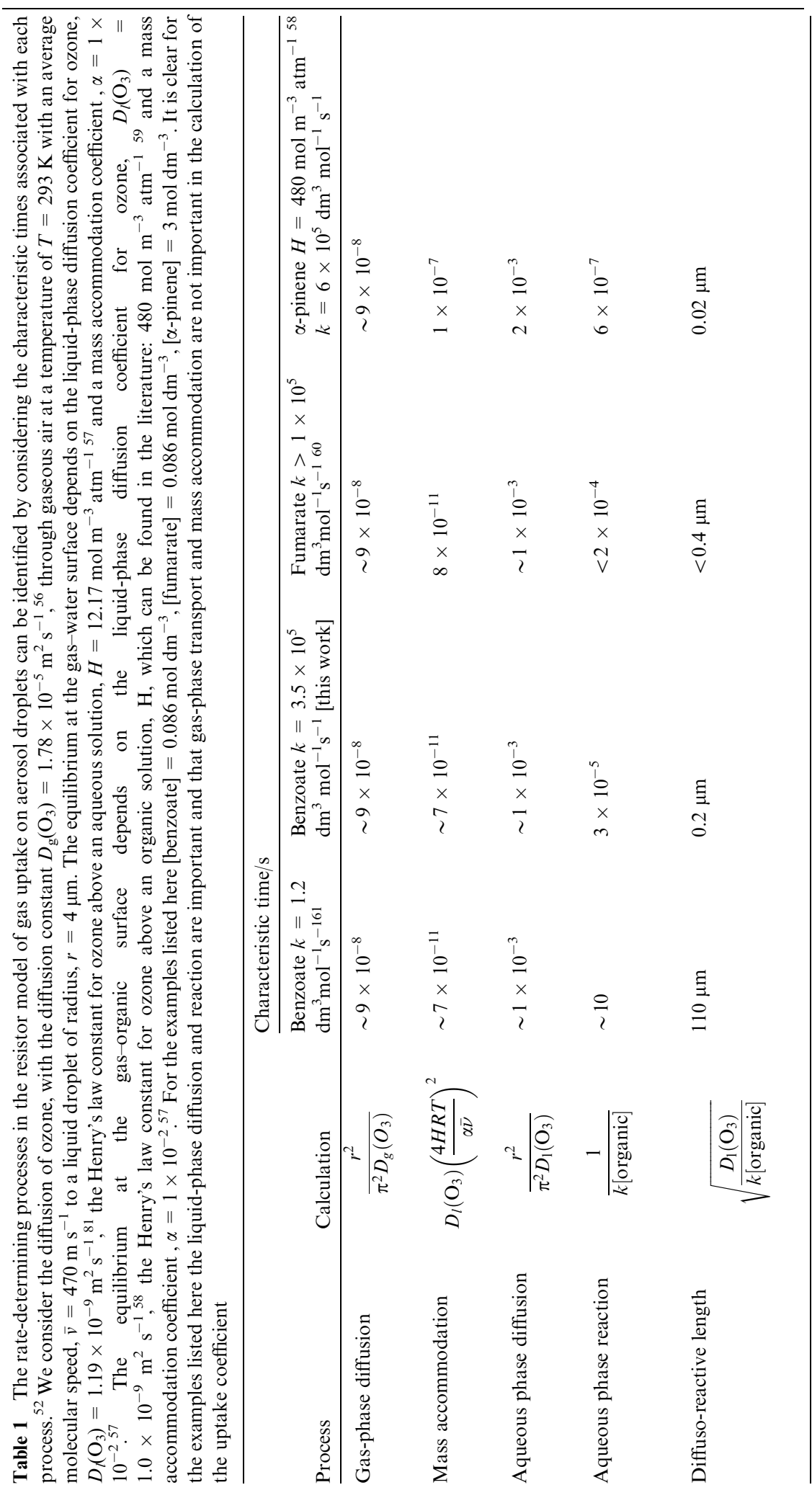


where $\nabla^{2}$ represents the Laplace operator. Smith et al. ${ }^{58}$ demonstrated that two analytical solutions can be found to eqn (III), based on work by Worsnop et al. ${ }^{51}$ One solution (eqns (IV) and (V)) is obtained for fast diffusion of ozone in the particle (i.e. the uptake is controlled by a 'slow' reaction):

$$
\text { [organic }_{t}=[\text { organic }]_{t=0} e^{-P\left(\mathrm{O}_{3}\right) H k t}
$$

and

$$
\gamma=\frac{4 H R T r k}{3 \bar{\nu}}[\text { organic }]
$$

where $P\left(\mathrm{O}_{3}\right)$ is the partial pressure of ozone in the gas-phase and [organic] is the concentration of the organic compound in the liquid-phase droplet, all other variable are as before. This solution is valid when the diffuso-reactive length is greater than the particle radius $(l>r)$.

A second solution has been suggested ${ }^{51,58}$ for a situation when the diffusion of ozone in the droplet is the rate-limiting step and the uptake is controlled by 'fast' reaction, i.e. the diffuso-reactive length is small compared to the droplet radius $(l \ll r)$ :

$$
{\sqrt{[\text { organic }]_{t}}}_{t}=\sqrt{[\text { organic }]_{t=0}}-\frac{3 P\left(\mathrm{O}_{3}\right) H \sqrt{k D_{l}\left(\mathrm{O}_{3}\right)}}{2 r} t
$$

and

$$
\gamma=\frac{4 R T}{\bar{\nu}} H \sqrt{k D_{l}\left(\mathrm{O}_{3}\right)} \sqrt{[\text { organic }]}
$$

As noted by Smith et al. ${ }^{58}$ a plot $\sqrt{\frac{[\text { organic }]_{t}}{[\text { organic }]_{t=0}}}$ as a function of time, $t$, has an intercept of unity and a gradient of $\frac{3 P\left(\mathrm{O}_{3}\right) H \sqrt{k D_{l}\left(\mathrm{O}_{3}\right)}}{2 r \sqrt{[\text { organic }]_{t=0}}}$. The quantity $H \sqrt{k D_{l}\left(\mathrm{O}_{3}\right)}$ may thus be obtained and then used in eqn (VII) to calculate the experimental uptake coefficient for the reaction with ozone without having to determine the Henry's law or diffusion constant for ozone in a concentrated solution, or determine the rate coefficient for reaction of ozone with organic. If $H$ and $D_{l}\left(\mathrm{O}_{3}\right)$ are known, it is possible to calculate the bimolecular rate coefficient, $k$, for reaction of ozone with the organic species in solution, although this was not the primary aim of the work presented here.

Table 1 lists the diffuso-reactive lengths for the chemical systems studied (fumarate, benzoate and $\alpha$-pinene). A comparison of the diffuso-reactive lengths with the particle radius suggests that the concentration-time data for fumarate and $\alpha$-pinene should be fitted to $\sqrt{\frac{[\text { organic }]_{t}}{\left[\text { organic }_{t=0}\right.}}$ versus $t$ and the concentration-time data for benzoate to $\ln \left(\frac{[\text { Organic }]_{t}}{[\text { Organic }]_{t=0}}\right)$ versus $t$ for $k_{2}=1.2 \mathrm{dm}^{3} \mathrm{~mol}^{-1} \mathrm{~s}^{-1}$ and to $\sqrt{\frac{[\text { organic }]_{t}}{[\text { organic }]_{t=0}}}$ versus $t$ for $k_{2}=3.5 \times 10^{5} \mathrm{dm}^{3} \mathrm{~mol}^{-1} \mathrm{~s}^{-1}$. In practice, the concentration-time data were fitted both to $\ln \left(\frac{[\text { Organic }]_{t}}{[\text { Organic }]_{t=0}}\right)$ versus $t$ and to $\sqrt{\frac{[\text { organic }]_{t}}{[\text { organic }]_{t=0}}}$ versus $t$ and the best fit was then analyzed.

3.1.1 Fumarate-ozone system. Fig. 1 shows a plot of particle radius and $\sqrt{\left[\text { [Fumarate }_{t}\right.}$ as a function of time, $t$, obtained when a droplet containing aqueous fumarate ions is exposed to gas-phase ozone. From the gradient of the plot of $\sqrt{\left[\frac{[\text { Fumarate }]_{t}}{[\text { Fumarate }]_{t=0}}\right.}$ versus $t$, the uptake coefficient, $\gamma=(1.1 \pm 0.7) \times 10^{-5}$, and the rate coefficient for reaction (1), $k_{1}=(2.7 \pm 2) \times 10^{5} \mathrm{dm}^{3} \mathrm{~mol}^{-1} \mathrm{~s}^{-1}$, were determined using eqn (VI). Table 2 gives the experimental conditions for the different systems investigated. The literature rate coefficient is $1 \times 10^{5} \mathrm{dm}^{3} \mathrm{~mol}^{-1} \mathrm{~s}^{-1}$ for a 


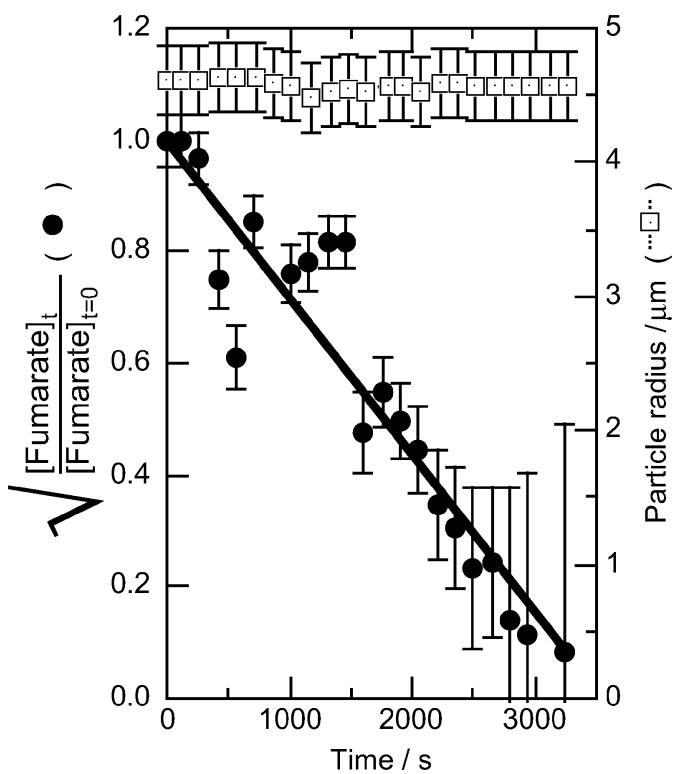

Fig. 1 A typical plot of $\sqrt{\frac{[\text { Fumarate }]_{t}}{\left[\text { Fumarate } t_{t=0}\right.}}$ and the radius of levitated droplet as a function of time. The $4.5 \mu \mathrm{m}$ radius particle was subjected to a relative humidity of $80 \%$ and an ozone mixing ratio of $1 \mathrm{ppm}$. The scatter in the points representing $\sqrt{\frac{[\text { Fumarate }]_{t}}{[\text { Fumarate }]_{t=0}}}$ at $t=700-1200 \mathrm{~s}$ is due interference in the Raman spectrum from large intensity morphological Raman resonances. The error bars on the radius data represent $0.25 \mu \mathrm{m}$ error in sizing the particle. The error on the values of $\sqrt{\frac{[\text { Fumarate }]_{t}}{[\text { Fumarate }]_{t=0}}}$ originates from the precision in the determination of [fumarate] by spectral stripping.

bulk aqueous solution at $\mathrm{pH}=5$ and the lower limit for $\mathrm{pH}=8$ was reported to be $>1 \times 10^{5} \mathrm{dm}^{3} \mathrm{~mol}^{-1} \mathrm{~s}^{-1}$. ${ }^{60} \mathrm{We}$ consider these values to be in good agreement with our result and this gives us confidence in our application of laser Raman tweezers for studying aerosol-gas-phase reactions. This finding also confirms

Table 2 Uptake coefficients, $\gamma$, for the heterogeneous reaction between gaseous $\mathrm{O}_{3}$ and aqueous droplets of sodium fumarate, sodium benzoate and organic droplets of $\alpha$-pinene/ dodecane and $\alpha$-pinene/pentadecane mixtures. The second-order rate coefficients, $k$, for the solution-phase reaction between ozone and aqueous sodium fumarate, sodium benzoate and organic-phase $\alpha$-pinene are also reported

\begin{tabular}{|c|c|c|c|c|c|c|c|}
\hline System & $r / \mu \mathrm{m}$ & $\begin{array}{l}P\left(\mathrm{O}_{3}\right) \\
(\mathrm{ppm})\end{array}$ & $\begin{array}{l}\text { Relative } \\
\text { humidity } \\
(\%)\end{array}$ & $\begin{array}{l}\text { Initial } \\
\text { mole } \\
\text { fraction }\end{array}$ & $\gamma$ & $k_{2} / \mathrm{dm}^{3} \mathrm{~mol}^{-1} \mathrm{~s}^{-1}$ & \\
\hline Fumarate & $4-5$ & 1.0 & 80 & $>0.0015$ & $(1.1 \pm 0.7) \times 10^{-5}$ & $(2.7 \pm 2) \times 10^{5}$ & \\
\hline Benzoate & $3-4$ & 1.0 & 60 & $>0.0015$ & $(1.5 \pm 0.7) \times 10^{-5}$ & $(3.5 \pm 3) \times 10^{5}$ & \\
\hline & & & & & & $\begin{array}{l}H=80 \\
\mathrm{~mol} \mathrm{~m}^{-3} \mathrm{~s}^{-1}\end{array}$ & $\begin{array}{l}H=480 \\
\mathrm{~mol} \mathrm{~m}^{-3} \mathrm{~s}^{-1}\end{array}$ \\
\hline $\begin{array}{l}\alpha \text {-pinene/ } \\
\text { Dodecane }\end{array}$ & $4-8$ & 0.7 & 30 & $\sim 0.59$ & $(4.0 \pm 0.7) \times 10^{-3}$ & $(1.6 \pm 0.6) \times 10^{7}$ & $(5 \pm 2) \times 10^{5}$ \\
\hline$\alpha$-pinene/ & $4.7-4.9$ & 0.4 & 60 & $\sim 0.66$ & $(3.0 \pm 0.9) \times 10^{-3}$ & $(1 \pm 0.5) \times 10^{7}$ & $(3 \pm 1) \times 10^{5}$ \\
\hline $\begin{array}{l}\text { Pentadecane } \\
\alpha \text {-pinene/ } \\
\text { Pentadecane }\end{array}$ & $5-7.5$ & 0.9 & 10 & $\sim 0.93$ & $(7.5 \pm 1.3) \times 10^{-3}$ & $(3 \pm 1) \times 10^{7}$ & $(9 \pm 3) \times 10^{5}$ \\
\hline
\end{tabular}




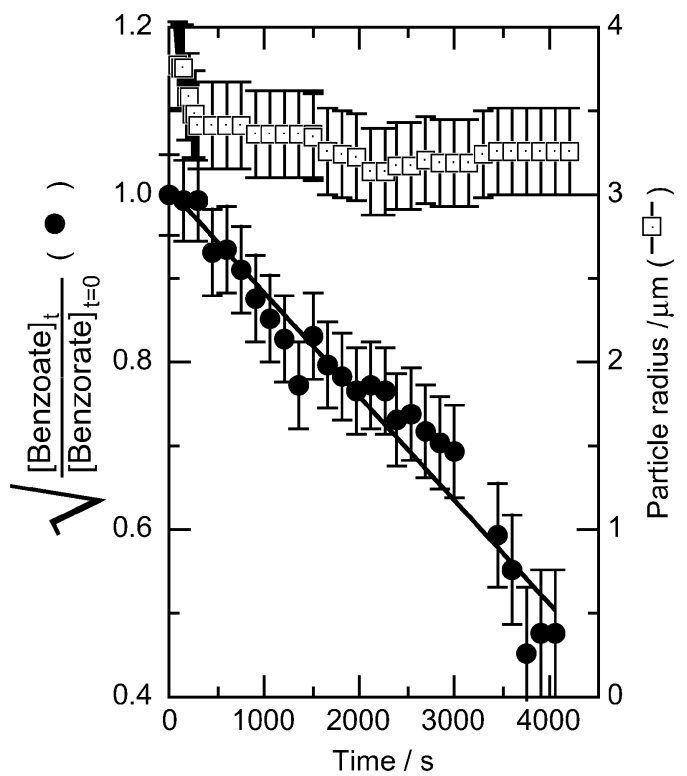

Fig. 2 A typical plot of $\sqrt{\frac{[\text { Benzoate }]_{t}}{\left[\text { Benzoate }_{t=0}\right.}}$ and the radius of levitated droplet as a function of time. The $3.8 \mu \mathrm{m}$ radius particle was subjected to a relative humidity of $60 \%$ and $\left[\mathrm{O}_{3}\right]$ of $1 \mathrm{ppm}$. The error bars on the radius data represent $0.25 \mu \mathrm{m}$ error in sizing the particle. The error on the values of $\sqrt{\frac{[\text { Benzoate }]_{t}}{\left[\text { Benzoate } t_{t=0}\right.}}$ originates from the precision in the determination of [benzoate] by spectral stripping.

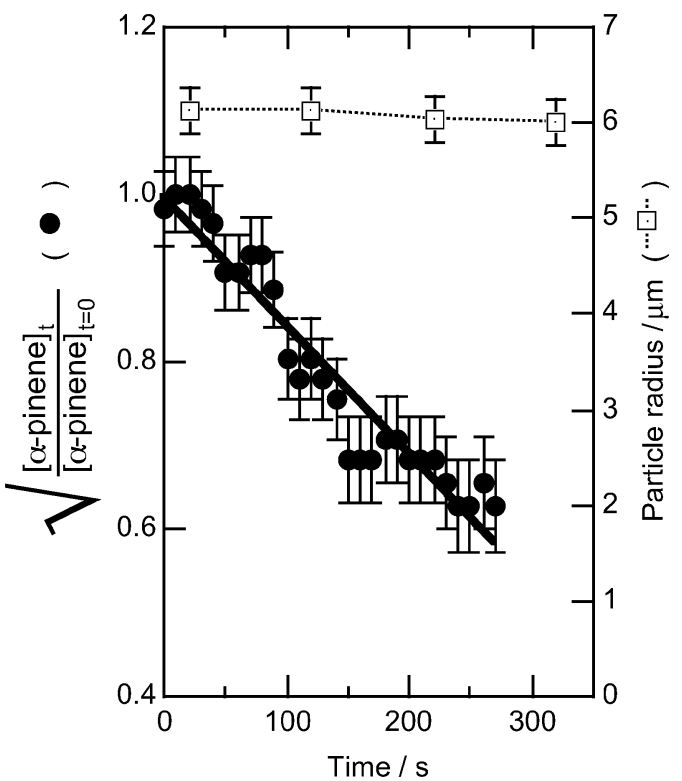

Fig. 3 A typical plot of $\sqrt{\left.\frac{[\alpha-\text {-pinene }]_{t}}{[\alpha-p i n e n e}\right]_{t=0}}$ and the radius of levitated droplet as a function of time. The $6.1 \mu \mathrm{m}$ radius particle was subjected to a relative humidity of $10 \%$ and $\left[\mathrm{O}_{3}\right]$ of $0.9 \mathrm{ppm}$. The error bars on the radius data represent $0.25 \mu \mathrm{m}$ error in sizing the particle. The error on the values of $\sqrt{\frac{[\alpha-\text { pinene }]_{t}}{[\alpha-\text { pinen }]_{t=0}}}$ originates from the precision in the determination of $[\alpha$-pinene] by spectral stripping. 
that the reaction between fumarate and ozone occurs in the bulk of the droplet and can be described by eqn (VI) and (VII). Our results are based on the analysis of four experiments in detail; altogether we studied 20 droplets, with each showing similar behaviour and giving similar values. The errors in the uptake coefficient and the value of $k_{1}$ are equal to a standard deviation of all the measurements of these quantities.

3.1.2 Benzoate-ozone system. The uptake of ozone on aqueous droplets containing benzoate ions was measured as $\gamma=(1.5 \pm 0.7) \times 10^{-5}$. The uptake coefficient was obtained from analysing six droplets in detail and using eqn (VI) and (VII) in conjunction with a plot of $\sqrt{\frac{[\text { Benzoate }]_{t}}{\left[\text { Benzoate } t_{t=0}\right.}}$ as a function of time, exemplified in Fig. 2. In all 25 droplets were studied. Eqn (VI) also allows the aqueous bimolecular rate coefficient for reaction (2) to be calculated as $k_{2}=(3.5 \pm 3) \times 10^{5} \mathrm{dm}^{3} \mathrm{~mol}^{-1} \mathrm{~s}^{-1}$. There is one reported literature value for the rate coefficient for reaction (2): $k_{2}=(1.2 \pm 0.2) \mathrm{dm}^{3} \mathrm{~mol}^{-1} \mathrm{~s}^{-1} .{ }^{61}$ The difference between our value for $k_{2}$ and the published value is considered in the Discussion section. The errors in the uptake coefficient and the value of $k_{2}$ are equal to a standard deviation of all the measurements of these quantities.

3.1.3 $\alpha$-pinene-ozone system. The uptake coefficient of ozone on a droplet which is a mixture of long-chain alkane and $\alpha$-pinene was measured to be $3.0-7.5 \times 10^{-3}$. Table 2 lists the values obtained when the organic solvent was changed from dodecane to pentadecane and the mole fraction of $\alpha$-pinene was altered. Fig. 3 gives a typical plot of $\sqrt{\frac{[\alpha-\text {-Pinene }]_{t}}{[\alpha-\text { Pinene }]_{t=0}}}$ as a function of time for the reaction (3). Eqn (VI) was used to extract a rate coefficient for reaction (3), $k_{3}$, from plots such as Fig. 3. Table 2 lists the rate coefficients measured in a series of experiments studying 30 droplets, 10 droplets in detail. Values of $k_{3}$ were determined to be $3-9 \times 10^{5} \mathrm{dm}^{3}$ $\mathrm{mol}^{-1} \mathrm{~s}^{-1}$, using a value for the Henry's law coefficient of $H=80 \mathrm{~mol} \mathrm{~m}^{-3} \mathrm{~atm}^{-1} .59$ For $H=480 \mathrm{~mol} \mathrm{~m}^{-3} \mathrm{~atm}^{-1},{ }^{58} k_{3}$ was found to be $1-3 \times 10^{7} \mathrm{dm}^{3} \mathrm{~mol}^{-1} \mathrm{~s}^{-1}$. The values of the rate coefficient $k_{3}$ and the uptake coefficient are reported as ranges to reflect the values measured over particles with different sizes and compositions, i.e. it may not be meaningful to simply average these values.

\subsection{Particle size changes}

During the oxidation of aqueous fumarate ions by ozone the droplet radius was not found to change significantly. The maximum size change was $12 \%$. Size changes are not correlated with the amount of fumarate in the droplet or the extent of the reaction. This result implies the hygroscopicity of the droplet, as described by Köhler theory, ${ }^{4}$ has changed very little over the course of the oxidation of the aqueous organic anion.

Aqueous benzoate droplets trapped in the laser tweezers also showed no dramatic change in size upon oxidation by ozone. Over the course of the reaction about half of the experiments demonstrated a very slow monotonic decrease in droplet radius (typically $<5 \%$ ). This decrease was not considered to be significant. It was concluded that, similar to the fumarate system, the oxidation of benzoate in solution did not cause a large change in the hygroscopicity of the droplet.

The kinetics of the reaction of pure $\alpha$-pinene droplets with gas-phase ozone could not be studied as pure $\alpha$-pinene droplets $(3-10 \mu \mathrm{m}$ radius) evaporated rapidly. Reactions of droplets of $\alpha$-pinene/dodecane mixtures with gas-phase ozone showed a gentle decrease in radius (about $1-2 \mu \mathrm{m}$ ) with time but monitoring the droplet size of $\alpha$-pinene/dodecane droplets and pure dodecane droplets in the absence of ozone also gives a decrease in radius with time. Monitoring the Raman spectra with time for the $\alpha$-pinene/dodecane mixtures demonstrates that the volatile $\alpha$-pinene is being lost by 
evaporation. The droplets of $\alpha$-pinene and the larger alkane pentadecane were subject to significantly lower evaporation rates. For all the experimental runs analysed, the loss of $\alpha$-pinene due to reaction with ozone was at least a factor of four larger than the loss due to evaporation. Reactions of ozone with $\alpha$-pinene/ pentadecane droplets show no discernable size change $(\ll 0.5 \mu \mathrm{m})$ during the oxidation process.

\subsection{Products}

In all cases exposure to gas-phase ozone caused a loss in the amount of organic reactant present in the trapped droplet, as followed by Raman spectroscopy. The products of the reactants that remained in the droplet were observed by Raman spectroscopy.

3.3.1 Fumarate-ozone system. Only one product peak was observed for oxidation of fumarate ions by ozone in aqueous droplets. The peak (at $1065 \mathrm{~cm}^{-1}$ ) was small and consistent with aqueous carbonate anions; other carbonate peaks (expected at $\sim 1436$ and $684 \mathrm{~cm}^{-1}$ ) are less intense and were not observed. ${ }^{62}$ No other product peaks were observed suggesting that either volatilisation or consumption by secondary reactions may have occurred, as discussed later.

3.3.2 Benzoate-ozone system. No products were observed for the reaction between ozone and aqueous droplets containing the benzoate anion. The final products of the reaction must have volatilised, be Raman inactive, or present in concentrations beneath the detection limit for the compound by Raman spectroscopy with the experimental set-up employed. To preserve electrical neutrality in the system one of the products must be an anion and hence non-volatile.

3.3.3 $\alpha$-pinene-ozone system. The Raman spectrum recorded for a $\alpha$-pinene/ pentadecane droplet before and after oxidation with ozone is given in Fig. 4 . The figure shows product peaks for new functional groups between 1600 and $1800 \mathrm{~cm}^{-1}$. In this region there are several new bands associated with the $\mathrm{C}=\mathrm{O}$ bond deformation. Comparison of spectra (c) and (a) also demonstrates that the $\mathrm{C}=\mathrm{C}$ bond stretch of $\alpha$-pinene has been removed in oxidation by ozone. The bands associated with $\mathrm{CH}_{2}$ and $\mathrm{CH}_{3}$ deformation $\left(<1500 \mathrm{~cm}^{-1}\right)$ have similar wavenumbers similar to those observed for $\alpha$-pinene suggesting that the product structure may not be too different from the starting material.

\section{Discussion}

\subsubsection{Uptake coefficients}

To the Authors' knowledge the uptake coefficients for ozone on for aqueous droplets of fumarate and benzoate solutions have not been previously measured. It should be noted that the uptake coefficients reported here do not take into account any uptake of ozone owing to hydroxide anions in solution and should thus be interpreted as upper limits. Uptake coefficients for $\alpha$-pinene have been determined previously. ${ }^{63}$ Measurements of the uptake of ozone on $\alpha$-pinene films at temperatures lower than $-30{ }^{\circ} \mathrm{C}$ gave values of $\gamma=2-2.5 \times 10^{-3} .{ }^{63}$ The values measured here (reported in Table 2) are broadly in agreement with the earlier determination giving us confidence in our method.

\subsubsection{Liquid-phase bimolecular rate coefficients}

The kinetic scheme used to measure the uptake coefficients allows the liquid-phase bimolecular rate coefficient for the reaction between ozone and fumarate, benzoate 


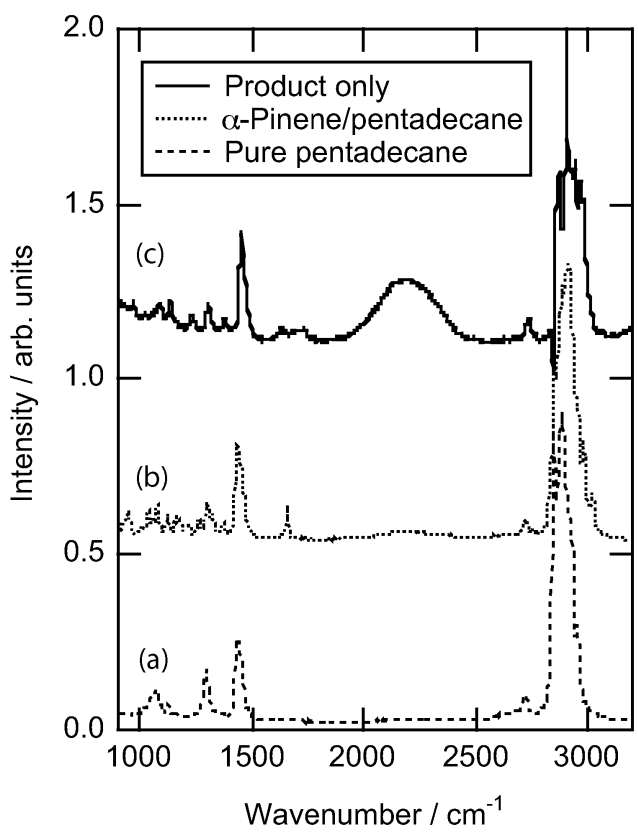

Fig. 4 Raman spectra (intensity as a function of the relative wavenumber) of (a) a pure pentadecane droplet, (b) a droplet of $\alpha$-pinene and pentadecane before reaction with ozone, mole fraction of $\alpha$-pinene is $\sim 0.66$, and (c) the Raman spectrum obtained after reaction with ozone, from which the reactants ( $\alpha$-pinene and pentadecane) have been subtracted. Spectrum (c) has several product peaks in the region $1600-1800 \mathrm{~cm}^{-1}$ characteristic of $\mathrm{C}=\mathrm{O}$ stretches. The peaks characteristic of the carbon-carbon double bond stretches in $\alpha$-pinene can be found in spectrum (b) at $1640 \mathrm{~cm}^{-1}$, and the two peaks between 3000 and $3100 \mathrm{~cm}^{-1}$ are gone in spectrum (c). The broad feature centered on $2200 \mathrm{~cm}^{-1}$ in spectrum (c) is stray light used to image the droplet/particle and can be removed by subtraction of background signal. The sharp feature at $2850 \mathrm{~cm}^{-1}$ in spectrum (c) is a morphological Raman resonance, and is included to demonstrate its occurrence in some spectra. The particle studied had $4.7 \mu \mathrm{m}$ radius, the relative humidity was $10 \%$ and $\left[\mathrm{O}_{3}\right]$ was at $0.4 \mathrm{ppm}$.

or $\alpha$-pinene to be measured. This analysis is a secondary aim of the work presented here. It should be noted that the precision (and accuracy) with which such a rate coefficient can be determined relies on precise (and accurate) measurement or knowledge of the particle size, ozone partial pressure, Henry's law constant and diffusion constant for ozone in the droplet, i.e. the parameters in eqn (VI). From the slope of a graph such as Fig. 2, i.e. $\sqrt{\frac{[\text { organic }]_{t}}{[\text { organic }]_{t=0}}}$ versus $t$, the bimolecular rate coefficient can be determined as,

$$
k=\frac{\sqrt{[\text { organic }]_{t=0}}}{D_{l}\left(\mathrm{O}_{3}\right)}\left(\frac{2 r \times \text { slope }}{3 P\left(\mathrm{O}_{3}\right) H}\right)^{2} .
$$

The Henry's law coefficient for ozone and the partial pressure of ozone near the particle may not be well known and the determination of $k$ depends on the square of these values. With these caveats in mind, it is worth recording that the value of the rate coefficient for the aqueous-phase reaction of fumarate with ozone determine in this work $\left(k_{1}=(2.7 \pm 2) \times 10^{5} \mathrm{dm}^{3} \mathrm{~mol}^{-1} \mathrm{~s}^{-1}\right)$ is consistent with the previous measurement $k_{1}>1 \times 10^{5} \mathrm{dm}^{3} \mathrm{~mol}^{-1} \mathrm{~s}^{-1}$. ${ }^{60}$ It should be noted that in order to obtain uptake coefficients from our data, it is not required to calculate $H, D_{l}\left(\mathrm{O}_{3}\right)$ or $k$.

The bimolecular rate coefficient measured for the aqueous-phase reaction between ozone and benzoate, $k_{2}=3.5 \times 10^{5} \mathrm{dm}^{3} \mathrm{~mol}^{-1} \mathrm{~s}^{-1}$, does not agree with the 
literature value of $1.2 \mathrm{dm}^{3} \mathrm{~mol}^{-1} \mathrm{~s}^{-1}$. ${ }^{61}$ However, it is not clear if the literature value is for the reaction of ozone with benzoic acid rather than the benzoate anion. ${ }^{61}$ The rate coefficient for the reaction of an oxidant with the carboxylate anion in solution is often several orders of magnitude larger than that for the corresponding carboxylic acid, i.e. the reaction kinetics of organic acids are extremely $\mathrm{pH}$ dependent. ${ }^{60,61}$ Inspection of Table 1 shows that for the literature value, the diffuso-reactive length would be much larger than the particle radius (i.e. fast diffusion of $\mathrm{O}_{3}$ would occur throughout the particle). The work of Smith et al. ${ }^{58}$ would then suggest that the loss of benzoate should be fitted to the following equation

$$
[\text { benzoate }]_{t}=[\text { benzoate }]_{t=0} e^{\left(P\left(\mathrm{O}_{3}\right) H k t\right)}
$$

and not to eqn (VI). However, eqn (VI) provides a better fit to the data than eqn (VIII), although both equations can be fitted. Using eqn (VIII) to obtain the rate coefficient, $k_{2}$, for the reaction between ozone and benzoate gives values of $\sim 1 \times 10^{5}$ $\mathrm{dm}^{3} \mathrm{~mol}^{-1} \mathrm{~s}^{-1}$ and diffuso-reactive lengths that are smaller than the particle radius, so that application of eqn (VIII) becomes invalid. We thus conclude that the large value for the rate coefficient we derived for the reaction between ozone and benzoate is not an error due to incorrect application of the equations suggested by Smith et al. ${ }^{58}$

The bimolecular rate coefficient, $k_{3}$, for $\alpha$-pinene reacting with ozone determined here depends on the value of Henry's law coefficient taken for ozone in the organic solvent. There is no previously reported measured value of $k_{3}$ for comparison. However, using the methodology of structure-activity relationships for predicting gas-phase kinetic rate coefficients ${ }^{64-66}$ the value of $k_{3}$ should be similar or greater than that for ozone reacting with 2-methyl-2-butene. Williamson and Cvetanoic ${ }^{67}$ report a value of $k=2.6 \times 10^{5} \mathrm{dm}^{3} \mathrm{~mol}^{-1} \mathrm{~s}^{-1}$ for this reaction in a solvent of carbon tetrachloride, suggesting that $H=480 \mathrm{~mol} \mathrm{~m}^{-3} \mathrm{~atm}^{-1}$ is the most sensible choice of value of $H$ for our system and the rate coefficient $k_{3}=3-9 \times 10^{5}$ $\mathrm{dm}^{3} \mathrm{~mol}^{-1} \mathrm{~s}^{-1}$.

For the analysis of the decay of fumarate, benzoate and $\alpha$-pinene with time, we have assumed a bulk reaction of ozone with these compounds, since ozone is reasonably soluble in water and alkanes. However, for completeness it is valuable to illuminate why the reaction may not be happening at the surface of the droplet. Provided that ozone diffusion and mass accommodation of ozone are not ratelimiting, the appropriate equation to describe the loss of organic species in the particle with time (due to reaction with ozone) is ${ }^{58}$

$$
[\text { Organic }]_{t}=[\text { Organic }]_{t=0} e^{\left(\frac{-3 \delta^{2}}{r} P\left(\mathrm{O}_{3}\right) H k^{\text {surf }} t\right)},
$$

where $\delta$ is the depth of the surface layer and $k^{\text {surf }}$ is the second-order surface rate coefficient for reaction between organic species and ozone. In contrast to eqn (VI), the temporal decay of the reactant in the particle is exponential. For the reactions of benzoate and fumarate, eqn (VI) provides a convincingly better fit to the experimental data than eqn (IX). For $\alpha$-pinene eqn (VI) only provides a slightly better fit than eqn (IX). However, although the droplet sizes studied form a reasonably narrow size distribution (see Table 2), there is no dependence of the uptake coefficients on droplet size for the any of the reactions studied here, strong evidence that bulk reactions as opposed to surface reactions are occurring. The diffusion of the co-reactant (i.e. benzoate, fumarate, and $\alpha$-pinene) in the droplet has not been considered in this work and may have a slight effect on the value obtained for the uptake coefficients, as discussed by Smith et al. ${ }^{58,68}$ 


\subsubsection{Size changes}

The particles studied here did not undergo a large size change during reaction. In our previous work the same laser Raman tweezers technique recorded a striking size change following the oxidation of a thin layer of oleic acid on a saltwater droplet. ${ }^{5}$ Reactions in aerosol particles can alter the chemistry and thermodynamics of the particles and they might lose or gain water vapour from the atmosphere in line with Köhler theory. ${ }^{4}$ For the reactions of ozone with aqueous droplets of benzoate or fumarate, a large size change is not expected from Köhler theory as the number of anionic solutes is not changing and only the mass of these solutes is decreasing. A large change in size of the droplet during the oxidation of $\alpha$-pinene might have been expected, as the production of carboxylic acids would have likely caused a hydrophilic layer to form at the organic-air interface of the particle. However, a size change was not recorded and this finding gives some evidence that there may be some oligomerisation occurring within the particle. Oligomerisation reactions would prevent the formation of free hydrophilic carboxylic acids.

Very recently submitted work by Reid et al. [in press ${ }^{69}$ ] suggests the occurrence of possible errors in measuring particle size by bright-field microscopy owing to uncertainties in the position of the trapped aerosol in the optical trap. These potential errors were minimised in this work by ensuring that a proportion of the measurements of the particle size were recorded on sharply focussed images of the particles. By making small adjustments in the collimation optics, used in conditioning the laser beam prior to optical trapping, the particle was brought into the focal plane (calibrated with a graticule) ensuring that sizing had no optical artefact.

It should be noted that a series of "blank" experiments were undertaken to characterise chemical and size changes of the particles. The nascent aqueous particles of fumarate and benzoate in the absence of ozone would normally shrink (or occasionally grow) in size as water evaporated (or condensed) from (onto) the particles to equilibrate the relative humidity within the cell in line with Köhler theory. ${ }^{4}$ This equilibration normally took a few minutes, and the particle size would remain stable for 90 minutes i.e. for time scales greater those required for a kinetic experiment. The intensity of the Raman signal would stay constant whilst the size was stable (in the absence of morphologic Raman resonances). The particle in the cell may experience a local relative humidity that is higher than the relative humidity of the gas entering the cell as some particles held for extended periods of time ( $>3$ hours) tended to shrink further. For these particles it is assumed that the particle size initially responds to a local relative humidity in the cell that is wet from aerosol impacting on the cell walls. On long time scales the cell equilibrates with the lower relative humidity of the gas flow through the cell and thus the particle experiences a lower relative humidity and evaporates accordingly. On the time scales of the kinetics experiment this was not a detrimental effect. However, no work is presented here using Köhler theory as the relative humidity is not accurately known. Problems originating from the measurement of the relative humidity in laser tweezers cells have been reported before. ${ }^{37}$

\subsubsection{Products and mechanism of fumarate oxidation by ozone}

The liquid-phase reaction between the fumarate ions and ozone has been previously studied $^{70}$ and the direct products of the ozonolysis have been shown to be the glyoxylate anion and the 2-hydroperoxy-2-hydroxyacetate anion:

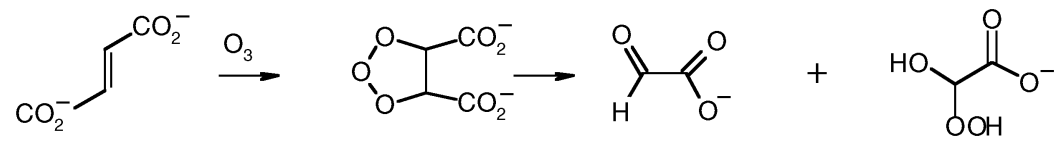


The 2-hydroperoxy-2-hydroxyacetate decays rapidly to formic acid (and hence formate in basic solutions) and carbon dioxide:<smiles>O=CC(=O)OCC(=O)O</smiles>

or overall

$$
\mathrm{CO}_{2} \mathrm{CH}=\mathrm{CHCO}_{2}{ }^{2-}+\mathrm{O}_{3} \rightarrow \mathrm{CHOCO}_{2}^{-}+\mathrm{CO}_{2}+\mathrm{HCO}_{2} \mathrm{H}+\mathrm{OH}^{-}
$$

The Raman spectra of glyoxylate and formate are not observed in our experiments, but there is a small sharp feature in the product spectrum that has been tentatively assigned to the carbonate anion, $\mathrm{CO}_{3}{ }^{2-}$. The 2-hydroperoxy-2-hydroxyacetate may also decompose to hydrogen peroxide and glyoxylate, but these two products can react rapidly to form formic acid, and carbon dioxide. Test experiments with nonanoic acid on a seawater particle with a $4 \mu \mathrm{m}$ radius demonstrated that the nonanoic acid could evaporate to below the detection limit on the time scale of minutes. However, in the $\mathrm{pH}$ conditions of these experiments any formic acid formed will exist as formate and not be volatile. Thus it appears that the formic acid or formate ion is consumed in a secondary reaction. Glyoxylate and formate are unlikely to react with ozone.

$$
\begin{gathered}
\mathrm{O}_{3}+\mathrm{HCO}_{2}^{-} \rightarrow \text { products, } k_{7}=100 \mathrm{dm}^{3} \mathrm{~mol}^{-1} \mathrm{~s}^{-161} \\
\mathrm{O}_{3}+\mathrm{HC}(\mathrm{O}) \mathrm{CO}_{2}{ }^{-} \rightarrow \text { products, } k_{8}=1.9 \mathrm{dm}^{3} \mathrm{~mol}^{-1} \mathrm{~s}^{-1}{ }^{61}
\end{gathered}
$$

However, the reaction of ozone with hydroxyl anions can produce $\mathrm{OH}$ radicals: ${ }^{71}$

$$
\begin{gathered}
\mathrm{O}_{3}+\mathrm{OH}^{-} \rightarrow \mathrm{HO}_{2}^{-}+\mathrm{O}_{2} \\
\mathrm{HO}_{2}^{-}+\mathrm{O}_{3} \rightarrow \mathrm{HO}_{2}+\mathrm{O}_{3}^{-\cdot} \\
\mathrm{O}_{3}^{-\cdot} \rightarrow \mathrm{O}^{-\cdot}+\mathrm{O}_{2} \\
\mathrm{O}^{-\cdot}+\mathrm{H}_{2} \mathrm{O} \rightarrow \mathrm{OH}^{-}+\mathrm{OH}^{-}
\end{gathered}
$$

Hydroxyl radicals react rapidly with formate and may react rapidly with glyoxylate ions,

$$
\begin{gathered}
\mathrm{OH}+\mathrm{HCO}_{2}^{-} \rightarrow \text { products, } k_{13}=2-5 \times 10^{9} \mathrm{dm}^{3} \mathrm{~mol}^{-1} \mathrm{~s}^{-1} 72 \\
\mathrm{OH}+\mathrm{HC}(\mathrm{O}) \mathrm{CO}_{2}{ }^{-} \rightarrow \text { products }
\end{gathered}
$$

and thus the presence of hydroxyl radical would reduce the concentration of formate and glyoxylate in the droplet to below the detection limit of our system. It should be noted that the first-order loss of ozone owing to reaction with the hydroxyl anion in the basic solution is slow compared to first-order loss with the fumarate anion. This secondary chemistry does thus not affect the determination of the kinetics of the reaction between ozone and formate, as shown below:

$$
\begin{gathered}
\mathrm{O}_{3}+\mathrm{CO}_{2} \mathrm{CH}=\mathrm{CHCO}_{2}{ }^{2-} \rightarrow \text { products } \\
k_{1}=1 \times 10^{5} \mathrm{dm}^{3} \mathrm{~mol}^{-1} \mathrm{~s}^{-1} 60\left[\mathrm{CO}_{2} \mathrm{CH}^{2-} \mathrm{CHCO}_{2}{ }^{2-}\right] \sim 0.09 \mathrm{~mol} \mathrm{dm}^{-3}, \\
k_{1} \times\left[\mathrm{CO}_{2} \mathrm{CH}=\mathrm{CHCO}_{2}{ }^{2-}\right] \sim 9000 \mathrm{~s}^{-1} \\
\mathrm{O}_{3}+\mathrm{OH}^{-} \rightarrow \mathrm{HO}_{2}{ }^{-}+\mathrm{O}_{2}, k_{9}=48 \mathrm{dm}^{3} \mathrm{~mol}^{-1} \mathrm{~s}^{-1}, 70 \\
{\left[\mathrm{OH}^{-}\right] \sim 1 \times 10^{-4} \mathrm{~mol} \mathrm{dm}^{-3}, \mathrm{pH}=10,} \\
k_{9} \times\left[\mathrm{OH}^{-}\right] \sim 0.005 \mathrm{~s}^{-1}
\end{gathered}
$$

\subsubsection{Products and mechanism of benzoate oxidation by ozone}

No products were observed for the reaction between ozone and benzoate. The oxidation of phenolic and benzoic species in aqueous solution by ozone produces 
intermediate compounds of fumaric and maleic acids and the resulting compounds are glyoxylic and formic acids. ${ }^{73-78}$ These species were not detected. Rate coefficients for reaction of fumarate and maleate with ozone are five orders of magnitude larger than that for reaction of benzoate with ozone, so that fumarate and maleate are unlikely to be observed. Reasons for the lack of product peaks in the Raman spectra owing to formate or glyoxylate production have been discussed earlier for the reaction of fumarate with ozone.

\subsubsection{Products and mechanism of $\alpha$-pinene oxidation by ozone}

The liquid-phase reaction between $\alpha$-pinene and ozone has been studied previously $^{79,80}$ and the major product detected was a hydroperoxide followed by verbenol, verbonone and pinoic acid. The Raman spectrum presented in Fig. 4 is not pinoic acid. Our investigation of the reaction of $\alpha$-pinene in pentadeacane with ozone is analogous to work performed by Mochida et al. ${ }^{81}$ who studied the oxidation of methyl oleate in a mixture of dioctyl adipate and myristic acid. Mochida et al. ${ }^{81}$ found that the products of these reactions were hydroperoxides, secondary ozonides, peroxides and oligomers generating high molecular weight species. The product peaks in Fig. 4(c) around $1600-1800 \mathrm{~cm}^{-1}$ are indicative of several $\mathrm{C}=\mathrm{O}$ carbonyl stretches. Not shown in Fig. 4 is the region of the spectrum between 800 and $1000 \mathrm{~cm}^{-1}$. This region was investigated in separate experiments to test for the presence of the peroxide stretch around $900 \mathrm{~cm}^{-1}$ — a strong signal was not observed, but in a few experiments there was a weak peak that may be tentatively assigned to peroxide. Our results are consistent with other studies of alkene oxidation by ozone suggesting the formation of several different carbonyl species and possibly peroxides. A study of the gas-phase oxidation of $\alpha$-pinene by ozone in the presence of aqueous inorganic particles has been undertaken by Gao et al. ${ }^{27}$ The study by Gao et $a l .{ }^{27}$ has parallels with our work with respect to the production distribution but differs from our study in two aspects: (a) Gao et al. study examined the gas-phase oxidation followed by partitioning of the product to the aerosol phase and then by further reaction; and (b) the particle phase was inorganic whereas ours is organic. Gao et $a l^{27}$ found by mass spectral analysis that four types of organic compounds were formed: organic acids, di-acid alkyl esters and hydroxy di-acids. They also obtained evidence for oligomer formation. Formation of oligomers was enhanced by an increase in particle acidity. In our study, we observe several different bands associated with $\mathrm{C}=\mathrm{O}$ stretches that may be indicative of groups similar to those seen by Gao et al. The occurrence of the tentative $\mathrm{O}-\mathrm{O}$ stretch may suggest secondary ozonide or peroxide formation. Czoschke et al. ${ }^{20}$ present FTIR spectra of the aerosol products of the oxidation of $\alpha$-pinene by ozone. They report that $\mathrm{CH}_{2}$ and $\mathrm{CH}_{3}$ stretches of the product species are similar to those found for $\alpha$-pinene and the existence of $\mathrm{C}=\mathrm{O}$ stretches and $\mathrm{OH}$ carboxylic stretches was also reported.

\section{Conclusions}

In this work we have shown that laser Raman tweezers can be used to measure uptake coefficients of gaseous oxidants on aqueous and organic droplets, whilst monitoring the size and composition of the droplet. Laser Raman tweezers are thus a powerful technique for the investigation of oxidation processes of atmospheric importance. The ability to study single droplets and not the average kinetics and chemistry of a distribution of droplets is a unique advantage of this technique.

The uptake of ozone on aqueous droplets containing benzoate or fumarate ions was found to be small. The droplets did not appear to change size following oxidation, suggesting cloud droplet sizes will not be influenced by these reactions, although the Authors fully acknowledge that only a limited range of relative 
humidities were probed. No evidence was found for oligomerization leading to HULIS formation at these high pHs. We have demonstrated that the laser Raman tweezers can be used successfully to study gas-aerosol reactions and we intend to study more complicated systems, such as those involving substituted phenols in the future.

The ozone-initiated oxidation of $\alpha$-pinene in an alkane was the first study using organic seed particles. The products did not differ from those found in earlier gas-phase studies of this reaction. Interestingly, no water uptake was observed, so that the hygroscopicity of the particle does not seem to have dramatically increased over the course of the reaction. Further studies are required to determine if the products formed are water-soluble or if oligomerisation is the dominant process.

\section{Acknowledgements}

The authors wish to thank the CCLRC under direct access grants CM11E2/05 and CM15C2/04 which have enabled use the laser tweezers apparatus at the Central Laser Facility, and Jonathan Reid for discussions on morphological resonances and particle sizing strategies. MDK wishes to thank NERC for support under NER/B/S/ 2003/00289. CP wishes to thank the Leverhulme Trust for support under the visiting scholar programme (grant $\mathrm{F} / 07537 / \mathrm{W})$.

\section{References}

1 U. Pöschl, Angew. Chem., Int. Ed., 2005, 44, 7520.

2 J. T. Houghton, Y. Ding, D. J. Griggs, M. Noguer, P. J. van der Linden and D. Xiaosu, Climate Change: The Scientific Basis, Cambridge University Press, Cambridge, 2001.

3 U. Lohmann and J. Feichter, Atmos. Chem. Phys., 2005, 5, 715.

4 M. L. Shulman, M. C. Jacobson, R. J. Carlson, R. E. Synovec and T. E. Young, Geophys. Res. Lett., 1996, 23, 277.

5 M. D. King, K. C. Thompson and A. D. Ward, J. Am. Chem. Soc., 2004, 126, 16710.

6 E. R. Graber and Y. Rudich, Atmos. Chem. Phys., 2006, 6, 729.

7 S. Decesari, M. C. Facchini, S. Fuzzi and E. Tagliavini, J. Geophys. Res., [Atmos.], 2000, 105, 1481.

8 A. Gelencser, T. Meszaros, M. Blazso, G. Kiss, Z. Krivacsy, A. Molnar and E. Meszaros, J. Atmos. Chem., 2000, 37, 173.

9 G. Kiss, E. Tombacz, B. Varga, T. Alsberg and L. Persson, Atmos. Environ., 2003, 37, 3783.

10 A. Gelencser, A. Hoffer, G. Kiss, E. Tombacz, R. Kurdi and L. Bencze, J. Atmos. Chem., 2003, 45, 25.

11 E. Dinar, T. F. Mentel and Y. Rudich, Atmos. Chem. Phys., 2006, 6, 5213.

12 A. Guenther, C. N. Hewitt, D. Erickson, R. Fall, C. Geron, T. Graedel, P. Harley, L. Klinger, M. Lerdau, W. A. McKay, T. Pierce, B. Scholes, R. Steinbrecher, R. Tallamraju, J. Taylor and P. Zimmerman, J. Geophys. Res., [Atmos.], 1995, 100, 8873.

13 J. H. Seinfeld and J. F. Pankow, Annu. Rev. Phys. Chem., 2003, 54, 121.

14 S. Hatakeyama, K. Izumi, T. Fukuyama and H. Akimoto, J. Geophys. Res., [Atmos.], 1989, 94, 13013.

15 D. Grosjean, Atmos. Environ., 1992, 26, 953.

16 T. Hoffmann, J. R. Odum, F. Bowman, D. Collins, D. Klockow, R. C. Flagan and J. H. Seinfeld, J. Atmos. Chem., 1997, 26, 189.

17 C. N. Cruz and S. N. Pandis, Atmos. Environ., 1997, 31, 2205.

18 H. J. Tobias and P. J. Ziemann, Anal. Chem., 1999, 71, 3428.

19 M. S. Jang, N. M. Czoschke, S. Lee and R. M. Kamens, Science, 2002, $298,814$.

20 N. M. Czoschke, M. Jang and R. M. Kamens, Atmos. Environ., 2003, 37, 4287.

21 A. Limbeck, M. Kulmala and H. Puxbaum, Geophys. Res. Lett., 2003, 30, 4.

22 Y. Iinuma, O. Boge, T. Gnauk and H. Herrmann, Atmos. Environ., 2004, 38, 761.

23 S. Koch, R. Winterhalter, E. Uherek, A. Kolloff, P. Neeb and G. K. Moortgat, Atmos. Environ., 2000, 34, 4031. 
24 M. P. Tolocka, M. Jang, J. M. Ginter, F. J. Cox, R. M. Kamens and M. V. Johnston, Environ. Sci. Technol., 2004, 38, 1428.

25 M. Kalberer, J. Yu, D. R. Cocker, R. C. Flagan and J. H. Seinfeld, Environ. Sci. Technol., 2000, 34, 4894.

26 J. Z. Yu, D. R. Cocker, R. J. Griffin, R. C. Flagan and J. H. Seinfeld, J. Atmos. Chem., 1999, 34, 207.

27 S. Gao, M. Keywood, N. L. Ng, J. Surratt, V. Varutbangkul, R. Bahreini, R. C. Flagan and J. H. Seinfeld, J. Phys. Chem. A, 2004, 108, 10147.

28 R. Omori, T. Kobayashi and A. Suzuki, Opt. Lett., 1997, 22, 816.

29 A. Biswas, H. Latifi, R. L. Armstrong and R. G. Pinnick, Opt. Lett., 1989, 14, 214.

30 R. Thurn and W. Kiefer, Appl. Spectrosc., 1984, 38, 78.

31 C. Mund and R. Zellner, ChemPhysChem, 2003, 4, 638.

32 C. Mund and R. Zellner, ChemPhysChem, 2003, 4, 630.

33 J. F. Lubben, C. Mund, B. Schrader and R. Zellner, J. Mol. Struct., 1999, 481, 311.

34 C. Mund and R. Zellner, J. Mol. Struct., 2003, 661, 491.

35 N. Jordanov and R. Zellner, Phys. Chem. Chem. Phys., 2006, 8, 2759.

36 D. McGloin, Philos. Trans. R. Soc. London, Ser. A, 2006, 364, 3521.

37 L. Mitchem, J. Buajarern, R. J. Hopkins, A. D. Ward, R. J. J. Gilham, R. L. Johnston and J. P. Reid, J. Phys. Chem. A, 2006, 110, 8116.

38 L. Mitchem, R. J. Hopkins, J. Buajarern, A. D. Ward and J. P. Reid, Chem. Phys. Lett., 2006, 432, 362.

39 J. Buajarern, L. Mitchem, A. D. Ward, N. H. Nahler, D. McGloin and J. P. Reid, J. Chem. Phys., 2006, 125.

40 L. Mitchem, J. Buajarern, R. J. Hopkins, A. D. Ward, R. J. J. Gilham, R. L. Johnston and J. P. Reid, J. Phys. Chem. A, 2006, 110, 8116.

41 J. P. Reid and R. M. Sayer, Chem. Soc. Rev., 2003, 32, 70.

42 R. J. Hopkins and J. P. Reid, J. Phys. Chem. B, 2006, 110, 3239.

43 M. D. Summers, J. P. Reid and D. McGloin, Opt. Express, 2006, 14, 6373.

44 E. Fallman and O. Axner, Appl. Opt., 1997, 36, 2107.

45 R. D. B. Gatherer, R. M. Sayer and J. P. Reid, Chem. Phys. Lett., 2002, 366, 34.

46 R. M. Sayer, R. D. B. Gatherer and J. P. Reid, Phys. Chem. Chem. Phys., 2003, 5, 3740 .

47 R. Symes, R. M. Sayer and J. P. Reid, Phys. Chem. Chem. Phys., 2004, 6, 474.

48 P. V. Danckwerts, Trans. Faraday Soc., 1950, 46, 300.

49 P. V. Danckwerts, Trans. Faraday Soc., 1951, 47, 1014.

50 P. V. Danckwerts, Gas-liquid reactions, McGraw-Hill, New York, 1970.

51 D. R. Worsnop, J. W. Morris, Q. Shi, P. Davidovits and C. E. Kolb, Geophys. Res. Lett., 2002, 29, 4.

52 B. J. Finlayson-Pitts and J. N. Pitts, Chemistry of the Upper and Lower Atmosphere, Academic press, San Deigo, 2000.

53 C. E. Kolb, D. R. Worsnop, M. S. Zahniser, P. Davidovits, T. R. Keyser, M. T. Leu, M. M. J. D. R. Hanson and A. R. Ravishankara, Progress and Problems in Atmospheric Chemistry, world Scientific Publishing, Singapore, 1995, p. 771.

54 D. R. Hanson, J. Phys. Chem. B, 1997, 101, 4998.

55 S. E. Schwartz and J. E. Freiberg, Atmos. Environ., 1981, 15, 1129.

56 Chemical and Physical Handbook, C. R. C. Press.

57 S. P. Sander, R. R. Friedl, D. M. Golden, M. J. Kurylo, G. K. Moorgat, H. Keller-Rudek, P. H. Wine, A. R. Ravishankara, C. E. Kolb, M. M. J. B. J. Finlayson-Pitts, R. E. Huie and V. L. Orkin, Chemical Kinetics and photochemical data for use in Atmospheric studies: Evaluation Number 15, Jet Propulsion Laboratory, Pasedena, 2006.

58 G. D. Smith, E. Woods, C. L. DeForest, T. Baer and R. E. Miller, J. Phys. Chem. A, 2002, 106, 8085.

59 T. Moise and Y. Rudich, J. Geophys. Res., [Atmos.], 2000, 105, 14667.

60 J. Hoigne and H. Bader, Water Res., 1983, 17, 185.

61 J. Hoigne and H. Bader, Water Res., 1983, 17, 173.

62 J. D. Frantz, Chem. Geol., 1998, 152, 211.

63 J. A. de Gouw and E. R. Lovejoy, Geophys. Res. Lett., 1998, 25, 931.

64 M. D. King, C. E. Canosa-Mas and R. P. Wayne, Phys. Chem. Chem. Phys., 1999, 1, 2231.

65 M. D. King, C. E. Canosa-Mas and R. P. Wayne, Phys. Chem. Chem. Phys., 1999, 1, 2239.

66 C. Pfrang, M. D. King, C. E. Canosa-Mas and R. P. Wayne, Atmos. Environ., 2006, 40, 1180.

67 D. G. Williamson and R. J. Cvetanovic, J. Am. Chem. Soc., 1968, 90, 3668. 
68 G. D. Smith, E. Woods, T. Baer and R. E. Miller, J. Phys. Chem. A, 2003, 107, 9582.

69 K. J. Knox, J. P. Reid, K. L. Hanford, A. J. Hudson and L. Mitchem, J. Opt. A: Pure Appl. Opt., 2007, 9, S180.

70 A. Leitzke, E. Reisz, R. Flyunt and C. von Sonntag, J. Chem. Soc., Perkin Trans. 2, 2001, 793.

71 L. Forni, D. Bahnemann and E. J. Hart, J. Phys. Chem., 1982, 86, 255.

72 G. V. Buxton, C. L. Greenstock, W. P. Helman and A. B. Ross, J. Phys. Chem. Ref. Data, 1988, 17, 513.

73 T. Poznyak and J. Vivero, Ozone-Sci. Eng., 2005, 27, 447.

74 T. Poznyak and B. Araiza, Ozone-Sci. Eng., 2005, 27, 351.

75 F. J. Beltran, F. J. Rivas and O. Gimeno, J. Chem. Technol. Biotechnol., 2005, 80, 973.

76 T. N. Murakami, M. Takahashi and N. Kawashima, Chem. Lett., 2000, 1312.

77 A. Mokrini, D. Ousse and E. Esplugas, Water Sci. Technol., 1997, 35, 95.

78 E. Gilbert, Z. Naturforsch., B: Chem. Sci., 1977, 32, 1308.

79 J. M. Encinar, F. J. Beltran and J. M. Frades, Chem. Eng. Technol., 1993, 16, 68.

80 J. M. Encinar, F. J. Beltran and J. M. Frades, Chem. Eng. Technol., 1994, 17, 187.

81 M. Mochida, Y. Katrib, J. T. Jayne, D. R. Worsnop and S. T. Martin, Atmos. Chem. Phys., 2006, 6, 4851. 